\title{
Classical-classical transfer: Effects of prior appetitive conditioning upon aversive conditioning in rabbits
}

\author{
MICHAEL J. SCAVIO, JR. \\ California State University, Fullerton, California 92634 \\ and \\ I. GORMEZANO \\ University of Iowa, Iowa City, Iowa 52242
}

\begin{abstract}
An appetitive-aversive transfer experiment with rabbits determined that prior paired and unpaired tone CS and water US presentations, given in jaw-movement (JM) conditioning, respectively facilitated and retarded the acquisition of the nictitating membrane (NM) CR when the tone was subsequently paired with a shock US. In addition, the unpaired tone and water deliveries reduced the level of $\mathrm{JM}$ conditioning that was undertaken following the completion of NM CR acquisition. Finally, the reacquisition of the NM CR was accompanied by a large savings effect in contrast to the failure of the JM CR to display reacquisition savings. When the present findings are compared to the results of previous work addressing the influence of prior NM conditioning procedures upon subsequent JM CR acquisition, an asymmetry in appetitive-aversive interactions is indicated. This asymmetry encourages a reinterpretation of the opponent-process explanation of appetitive-aversive interactions. Moreover, the observed effects of the unpaired CS suggest the operation of a salience factor.
\end{abstract}

According to the opponent-process model, which has been developed by several researchers (Gray, 1971; Konorski, 1967; Miller, 1963; Mowrer, 1960; Rescorla \& Solomon, 1967), appetitive and aversive motivational states exist and influence one another in an antagonistic fashion.' Increased activity in one state automatically produces decrements in the strength of the other state. The final quality and intensity of the motivation for behavior is then determined by the algebraic summation of all opposing appetitive and aversive sources. The opponentprocess model also assumes that a CS, through pairings with a reinforcer, acquires the affective value of that reinforcer. Consequently, the subsequent pairing together of a previously established affective CS with a hedonically opposite reinforcer should retard the development of conditioned behavior. Some opponent-process theorists (Gray, 1971; Konorski, 1967; Rescorla \& Solomon, 1967) have further proposed that a CS, given in an unpaired fashion with a reinforcer, acquires an affective value antipodal to the reinforcer. Therefore, prior unpaired

The research was supported by NSF Grant BNS 76-84561. The authors wish to acknowledge the contributions of Ellen Aycock and Pamela Scavio to the execution of the research. Requests for reprints should be addressed to either M. J. Scavio, Department of Psychology, California State University, Fullerton, California 92634, or I. Gormezano, Department of Psychology, University of Iowa, Iowa City, Iowa 52242.
$\mathrm{CS}$ and reinforcer deliveries are predicted to facilitate subsequent conditioning if the $\mathrm{CS}$ is paired with a reinforcer whose hedonic quality is opposed to the original reinforcer.

Evaluation of the opponent-process model has been accomplished through so-called appetitiveaversive interaction experiments in which the same $\mathrm{CS}$ is successively paired with affectively rival reinforcers. However, Dickinson and Pearce's (1977) recent review of the relevant work indicated the possibility that appetitive-aversive interactions are not symmetrical. While there is good evidence (e.g., Estes \& Skinner, 1941; Scavio, 1974) that presentations of a previously established aversive CS retard the conditioned performances of an appetitively reinforced response, the effects of appetitive CSs upon aversively reinforced responses have yielded mixed results. Some researchers (e.g., Goodkin, 1976; Konorski \& Szwejkowska, 1956) have reported a disruption in the conditioning of an aversively reinforced response to a CS which had been previously paired with an appetitive US. Yet, others (e.g., Bacon \& Bindra, 1967; O'Neill \& Biederman, 1974; Overmier \& Payne, 1971) have reported the opposite effect, namely, a facilitation in the conditioning of an aversively reinforced response to a CS previously paired with an appetitive US.

The present study completes a plan of research examining the symmetry of appetitive-aversive inter- 
actions utilizing the rabbit's jaw-movement (JM) and nictitating membrane (NM) conditioning paradigms. Scavio (1974) has found that paired tone CS and shock US deliveries, given in NM conditioning, decremented JM conditioning when the tone was subsequently paired with a water US. Moreover, Bromage and Scavio (1978) have observed the facilitation in JM conditioning when the tone CS had been given in an unpaired fashion with a shock US in NM conditioning. Accordingly, in the present work, the effects of prior paired and unpaired tone CS and water US deliveries, given in JM conditioning, were assessed upon NM CR formation when the tone and shock US were subsequently paired together. In addition, reacquisitions of the JM and NM CRs were undertaken following conditioning of the other response system. If appetitive-aversive interactions are symmetrical for the rabbit conditioning paradigms, as expected by the opponent-process model, then prior paired and unpaired tone and water presentations should, respectively, decrement and augment aversive NM CR formation. The opponentprocess prediction of the decrementing effect of prior paired tone and water presentations upon NM conditioning rests upon the assumed reduction in the aversive motivational strength of the shock induced by the tone, which is presumed to acquire antagonistic appetitive properties through its previous pairings with water. Furthermore, the predicted augmenting effect of prior unpaired tone and water deliveries upon NM conditioning should be due to an increase in the aversive motivational strength resulting from the hedonic compatibility between the shock and the tone, which is presumed to become aversive through the unpaired deliveries with water. If the present work should yield a deviation from the predicted symmetry of appetitive-aversive interactions, then re-examination of the opponent-process model is warranted.

\section{METHOD}

\section{Subjects \\ The subjects were 48 male and female New Zealand albino rabbits, 80-100 days old and each weighing about $2 \mathrm{~kg}$.}

\section{Apparatus}

The conditioning chambers, apparatus, and techniques for recording the jaw-movement response (JMR) have been described by Mitchell and Gormezano (1970), who detail procedures from the original specification (Smith, DiLollo, \& Gormezano, 1966). The apparatus and techniques for recording the nictitating membrane response (NMR) have been given by Coleman and Gormezano (1971), who detail departures from the original design (Gormezano, 1966; Gormezano, Schneiderman, Deaux, \& Fuentes, 1962). In brief, the conditioning chambers were fabricated from legal-sized, fireproof filing cabinets to which individual blowers, exhausts, and stimulus panels had been added. Before being placed in a conditioning chamber, each rabbit was positioned in a Plexiglas restraining box constructed with an adjustable back-plate, neck stock, and pinnae clamp.
}

The JMRs and NMRs were recorded by means of photoresistive transducers anchored on a muzzle-like headmount, which locked to a ring looped over the rabbit's pinnae. For JMR recording, one end of a Z-shaped piano-wire lever was passed through a 9-mm stainless steel wound clip attached to the tip of the rabbit's lower mandible. The other end of the lever, serving as a movable axle, was housed within an opaque Plexiglas cylinder. Inside the cylinder, the end of the lever terminated in the center of a Polaroid disk with variable translucent properties as a function of degree-arc location. The rotation of the axle lever, initiated by a JMR, changed the position of the Polaroid disk, which in turn affected the amount of illumination reaching the photocell. The NMR was monitored by connecting a small hook to a nylon loop sutured into the right nictitating membrane. The hook was coupled to the long arm of an $\mathbf{L}$-shaped wire level whose axle, attached to the short-arm of the wire lever, was housed in a photocell transducer assembly similar to the one used for JMR recording. The voltage outputs of the photocells, linearly related to the amount of jaw or membrane movement, were amplified and recorded on a Beckman six-channel, ink-writing dynograph operating at a paper speed of $250 \mathrm{~mm} / \mathrm{sec}$. The amplification factor yielded $1 \mathrm{~mm}$ of pen movement corresponding to $.5 \mathrm{~mm}$ of jaw or membrane movement.

The CS was an $89-\mathrm{dB}$ (re $20 \mu \mathrm{N} / \mathrm{m}^{2}$ ), 500-msec, $1,000-\mathrm{Hz}$ tone. The US for JM conditioning was a $1-\mathrm{ml}$ squirt of water delivered over a period of $300 \mathrm{msec}$ into the rabbit's oral cavity through a polyethelene cannula implanted in the left cheek. The US for NM conditioning was a $50-\mathrm{msec}, 3-\mathrm{mA}, 60-\mathrm{Hz}$ shock delivered through electrodes positioned $15 \mathrm{~mm}$ apart and $10 \mathrm{~mm}$ posterior to the external canthus of the rabbit's right eye. All stimulus events were timed by Iconix preset timers and relay units. The operation of the Iconix packages formed an and-gate arrangement with a seven-channel tape reader which determined the intertrial intervals.

\section{Procedure}

Seven days after arrival, each rabbit was placed in a restraining box so that the area around the right eye and cheek could be depilated. A length of 00 Ethicon monofilament nylon thread was sutured and tied to form a 2-mm-diam loop in the right membrane. Then each rabbit was anesthetized to allow receipt of the poly. ethelene cannula incised into the right cheek. On the 3 rd postoperative day, each rabbit was placed on a moderately severe water-deprivation regime which limited water intake to $60 \mathrm{ml}$ per day throughout the experiment. (Average daily water intake for 80-100-day-old rabbits is about $300 \mathrm{ml}$.) On the 6th postoperative day, 12 rabbits were randomly assigned to each of four groups and adapted to the conditioning apparatus for $45 \mathrm{~min}$. On the 7 th postoperative day, Stage 1 of the experiment was initiated. Table 1 shows the training procedures accorded to the various groups throughout all stages of the experiment.

In Stage 1, which lasted for 6 successive days, Group $P$ received 30 paired tone CS and water US presentations daily for the conditioning of the JMR. Group $U$ was given 30 explicitly unpaired tone CS and water US deliveries each day with the ordering of the tone and water subject to the restriction that, in each block of 10 events, an equal number of each type of stimulus occur with no more than three successive deliveries of the same stimulus allowed. Groups N and NN received no stimulus presentations and were simply confined in the conditioning chambers on each day for a time period corresponding to the length of a training session given to Groups $P$ and $U$.

In Stage 2, which began on the day following the completion of Stage 1 and lasted 4 successive days, Groups $P, U$, and N received 80 tone $C S$ and shock US pairings on each day for NM conditioning. During Stage 2, Group NN was again confined to the conditioning apparatus without stimulus presentations for an equivalent time period. Fifteen minutes after the conclusion of the last Stage 2 session, five tone-CS-alone presentations were given to all groups, with JMR recordings being taken. The purpose of these tone-alone trials was to ascertain whether the JM CR 
Table 1

Treatments Given to the Groups in the Four Stages of the Experiment

\begin{tabular}{lllll}
\hline Group & \multicolumn{1}{c}{ Stage 1 } & \multicolumn{1}{c}{ Stage 2 } & \multicolumn{1}{c}{ Stage 3 } & Stage 4 \\
\hline $\mathbf{P}$ & tone and water pairings & tone and shock pairings & tone and water pairings & tone and shock pairings \\
$\mathrm{U}$ & tone and water unpairings & tone and shock pairings & tone and water pairings & tone and shock pairings \\
$\mathrm{N}$ & no stimuli presented & tone and shock pairings & tone and water pairings & $\begin{array}{l}\text { tone and shock pairings } \\
\text { tone and shock pairings }\end{array}$ \\
$\mathrm{NN}$ & no stimuli presented & no stimuli presented & tone and water pairings & tond
\end{tabular}

Note-Five tone-alone presentations were given following Stages 2 and 3 to all groups with JM and NM responses being recorded, respectively.

survived membrane conditioning for Group $P$. In addition, the tone-alone trials determined for Group $N$ whether the Stage 2 tone and shock pairings had fortuitously allowed JM conditioning.

Stage 3 began on the next day with all groups receiving 30 tone CS and water US pairings daily for 6 consecutive days of JM conditioning. Again, $15 \mathrm{~min}$ following the last Stage 3 pairing, all groups obtained five tone-CS-alone presentations, with NMR recordings being taken. These tone deliveries assessed for Groups $P, U$, and $N$ whether the NM CR, acquired in Stage 2, had survived through Stage 3 JMR conditioning. Also, the tonealone presentations given to Group NN served to indicate whether the Stage 3 tone-and-water pairings had produced unintended NM conditioning. Finally, Stage 4 began $5 \mathrm{~min}$ following the termination of the last tone-CS-alone trial, with all groups receiving 30 tone-and-shock pairings for NM conditioning.

The CS-US interval on all paired trials in JM and NM conditioning was $500 \mathrm{msec}$. The intertrial intervals for $\mathrm{JM}$ conditioning were randomized at values of 80,90 , and $100 \mathrm{sec}$ with a mean of $90 \mathrm{sec}$. For Stage 1, the interevent intervals separating the unpaired tone and water deliveries were randomized at values of 40,45 , and $50 \mathrm{sec}$, with a mean of $45 \mathrm{sec}$. The intertrial intervals for NM conditioning were varied at values of 50,60 , and $70 \mathrm{sec}$, with a mean of $60 \mathrm{sec}$. Jaw or membrane movement of at least $1 \mathrm{~mm}$ during the 500 -msec duration of the tone $\mathrm{CS}$ on paired, unpaired, and CS-alone trials was scored as a CR. For Group $\mathbf{N}$ in Stage 1 and Group NN in Stages 1 and 2, response activity was monitored in blank 500 -msec time envelopes, which corresponded to the deliveries of the tone CS on paired trials.

\section{RESULTS AND DISCUSSION}

\section{Stage 1}

Figure 1 displays the percentage of JMRs for all groups over the 6 days of Stage 1 training. The toneand-water pairings given to Group $P$ produced substantial JM conditioning with a terminal acquisition level above $80 \%$. In contrast, Group $U$, given explicitly unpaired tone and water deliveries, showed only a minor increase in JMRs over the training days. Finally, Groups $\mathrm{N}$ and NN, both confined to the apparatus without tone or water presentations, maintained a daily baseline JMR activity rate of about $1 \%$. An analysis of variance was performed for all groups upon the percentage of JMRs in blocks of 10 trials on each day. Significant effects were found for Groups $[F(3,44)=39.37, p<.01]$, Days $[F(5,220)$ $=29.30, \mathrm{p}<.01]$, Blocks $[\mathrm{F}(2,88)=4.94, \mathrm{p}<.05]$, and the Groups by Days interaction $[F(15,220)=$ $12.31, p<.01]$. The significant Groups effect was further evaluated by a set of comparison tests conducted upon the overall group performance means. The resulting $F$ tests revealed the Groups $P(\bar{X}=$ $57 \%)$ and $U(\bar{X}=17 \%)$ were reliably different $(p<.01)$ from one another and clearly superior (ps $<.01)$ to Groups N $(\bar{X}=1 \%)$ and NN ( $\bar{X}=$ $1 \%$ ).

The changes in the tone CS produced by the Stage 1 training procedures can be related to the expectations of the opponent-process model. As previously discussed, the tone-and-water pairings given to Group $\mathbf{P}$ should have allowed for the acquisition of appetitive motivational properties to the tone. In contrast, the unpaired tone and water deliveries accorded to Group U should have established the tone with aversive motivational effects. The conditioning rates for the NMR in Stage 2 provided the opportunity to assess whether the presumed motivational properties of the paired and unpaired CS influence aversively reinforced behavior in a manner consistent with the predictions of the opponentprocess model.

\section{Stage 2}

Figure 2 presents the percentage of NMRs for all groups over the Stage 2 training days. Examination of the figure reveals that Groups $\mathrm{P}, \mathrm{U}$, and $\mathrm{N}$, all now exposed to tone-and-shock pairings, had differential conditioning rates. Relative to Group N, Group $P$ displayed greater increments in NM CR performance while Group $\mathrm{U}$ showed a more depressed pattern. Group NN, which continued to be confined

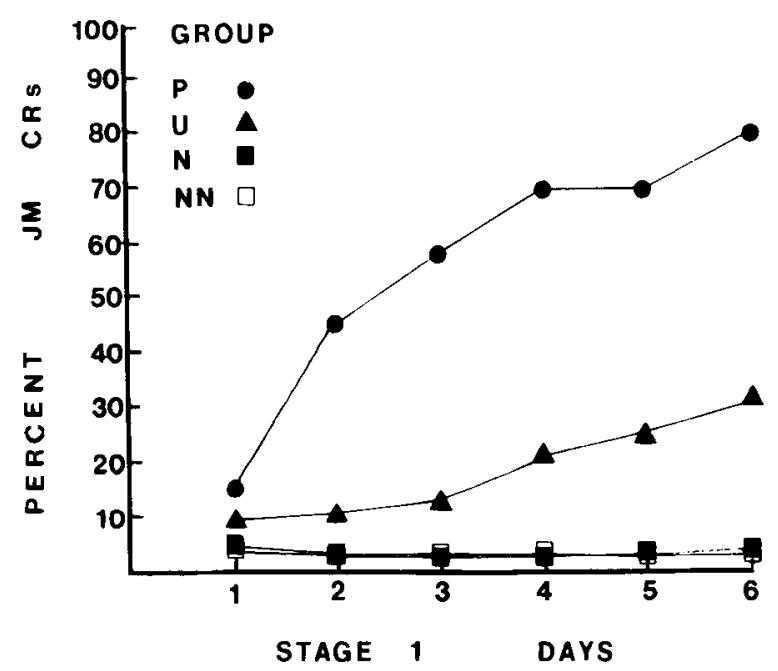

Figure 1. Mean percentage of jaw-movement (JM) CRs plotted for all groups over the Stage 1 training days. 


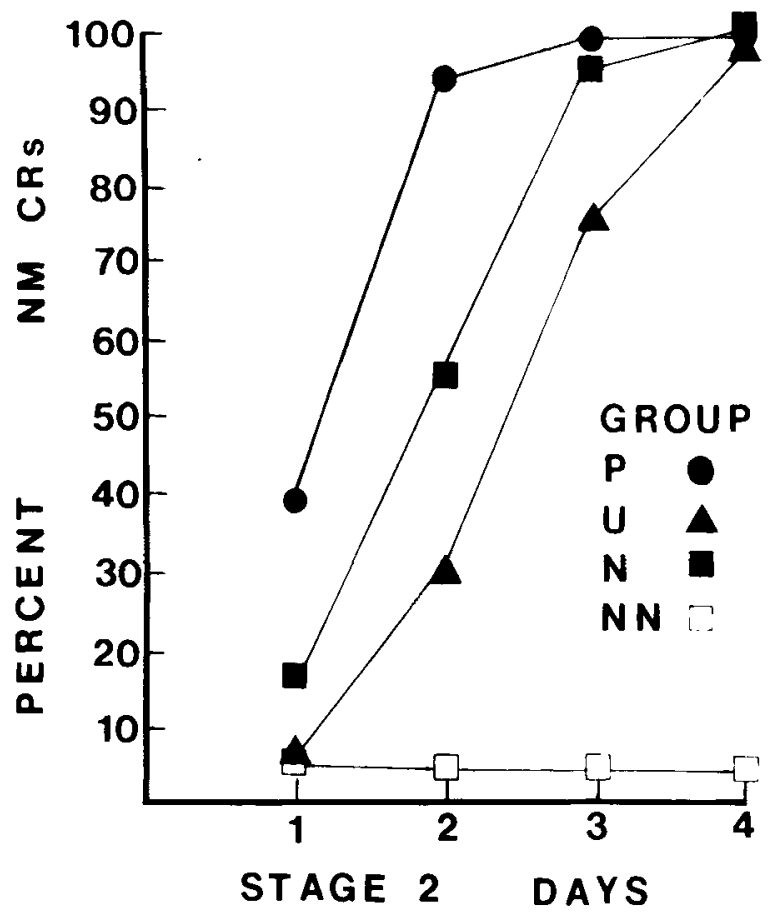

Figure 2. Mean percentage of nictitating membrane (NM) CRs plotted for all groups over the Stage 2 training days.

in the apparatus without stimulus presentations, maintained a daily NMR base rate of less than $4 \%$. An analysis of variance for Groups $P, U$, and $N$ upon percentage of NM CRs in daily blocks of 20 trials disclosed significant effects for $\operatorname{Groups}[\mathrm{F}(2,33)$ $=13.65, \mathrm{p}<.01]$, Days $[\mathrm{F}(3,99)=169.06, \mathrm{p}<.01]$, Blocks $[\mathrm{F}(3,99)=45.05, \mathrm{p}<.01]$, and the Days by Blocks interaction $[F(9,297)=8.65, p<.01]$. A set of comparison tests conducted upon the overall group means indicated tht Groups $P(\bar{X}=81 \%)$, $\mathrm{U}(\overline{\mathrm{X}}=53 \%)$, and $\mathrm{N}(\overline{\mathrm{X}}=66 \%)$ were all reliably different from one another ( $\mathrm{ps}<.02$ ). Thus, the data analyses substantiated that paired and unpaired tone CS and water US deliveries in Stage 1 facilitated and retarded, respectively, the development of the aversive NM CR to the tone.

The comparison of the present pattern of transfer effects with the results of the previously completed work shows that appetitive-aversive interactions for rabbit conditioning are asymmetrical. In agreement with the opponent-process model, paired (Scavio, 1974) and unpaired (Bromage \& Scavio, 1978) tone and shock presentations given in NM conditioning had decrementing and facilitating influences, respectively, upon appetitive JM conditioning to the tone. In contrast to the opponent-process model, the present findings indicated that paired and unpaired tone and water presentations given in JM conditioning facilitated and decremented, respectively, aversive NM conditioning to the tone.

Finally, five CS-alone presentations were administered to all groups upon the conclusion of Stage 2 conditioning. The JMR performance rates on these trials for Groups $\mathrm{P}, \mathrm{U}$, and $\mathrm{N}$ were found to be $6 \%$, $1 \%$, and $5 \%$, respectively. The performances were assessed by analysis of variance and were found not to be significantly different from the $2 \%$ base rate recorded for Group NN on the CS-alone trials. Therefore, the low frequency of JMRs for Group N indicated that this response was not acquired as part of Stage 2 NM conditioning. Additionally, the performance of Group P on the CS-alone trials, relative to its level at the conclusion of Stage 1, meant that the JM CR did not survive Stage 2 NM conditioning.

\section{Stage 3}

Figure 3 shows the percentage of JM CRs for all groups over the Stage 3 days. The conditioning performance for Group NN, which now received stimulus presentations for the first time, predominated over the other group rates. Group $N$, whose prior experience involved only Stage 2 NM conditioning, displayed lower daily $C R$ frequencies relative to Group NN until the final training session. Since Group P, exposed to both JM (Stage 1) and NM (Stage 2) conditioning, did not display an abrupt increase in JM CR performance, no reacquisition savings effect was obvious. Finally, Group U, which had unpaired tone and water deliveries (Stage 1) followed by NM conditioning (Stage 2), exhibited only slight improvements in JM CR performance and terminated Stage 3 with the lowest conditioning asymptote.

An analysis of variance, performed upon the percentage of JM CRs in 10-trial blocks on each day, revealed significant effects for Days $[F(5,220)=$ $13.62, \mathrm{p}<.01]$ and $\operatorname{Blocks}[\mathrm{F}(2,88)=6.47, \mathrm{p}<.01]$. Although the Groups effect only approached significance $(p<.07)$, a reliable Groups by Days interaction $[F(15,220)=2.18, p<.01]$ was obtained and

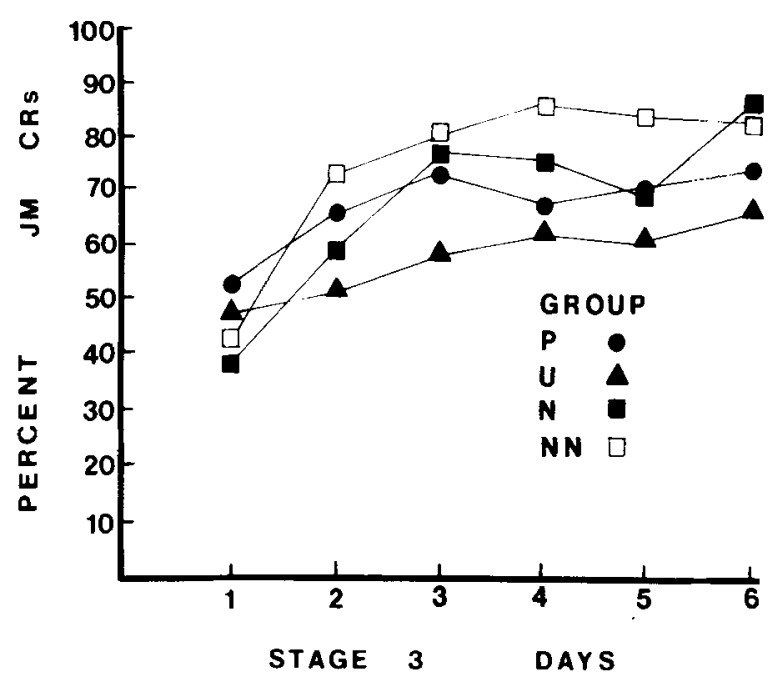

Figure 3. Mean percentage of jaw-movement (JM) CRs plotted for all groups over the Stage 3 training days. 
supported the observation of divergent JM CR performance functions over the training days. Two subsequent analysis of variance tests were calculated to locate the source of the interaction. The first, restricted to the initial 3 days of Stage 3, revealed the expected significant effects for Days $[F(2,88)=$ 28.33, $p<.01]$ but not a reliable Groups effects. The second, applied over the last 3 days of Stage 3, yielded a Groups effect $[F(3,44)=2.89, \mathrm{p}<.05]$. Follow-up comparison tests upon the group means over the last 3 days established that Group NN ( $\bar{X}$ $=80 \%)$ was superior $(\mathrm{p}<.05)$ to Group $\mathrm{U}(\overline{\mathrm{X}}=$ $57 \%)$, while Groups $P(\bar{X}=68 \%)$ and $N(\bar{X}=74 \%)$ were not significantly different from one another or to Groups NN and U.

A final analysis of variance comparing JM CR acquisition rates between Stage 1 (Group P) and Stage 3 (Group NN) indicated a significant Stage effect $[F(1,22)=6.92, p<.02]$. Since Groups $P$ and $\mathrm{NN}$ received their initial exposures to training in the form of JM conditioning, the reliable Stage effect is most likely due to the cumulative impact of water deprivation. Group P, which had an overall JM CR probability of $57 \%$ over the 6 days of Stage 1, was maintained on water deprivation for only 4 days prior to training. In contrast, Group NN, which had an overall JM CR probability of $76 \%$ over the 6 days of Stage 3, was exposed to the deprivation procedure for 14 days prior to training. The indication of the influence of water deprivation upon JM conditioning corroborates Mitchell and Gormezano's (1970) previous observation.

The inferior JM CR performance of Group $U$ in Stage 3 appears to stem from the retention across Stage 2 NM conditioning of specific inhibitory influences of unpaired tone and water presentations originally given in Stage 1. But, as discussed above, the unpaired tone and water deliveries of Stage 1 also produced retardation of aversive NM conditioning in Stage 2. The trans-reinforcer effects of unpaired tone and water presentations coupled with the retention of specific-reinforcer effects has not been previously disclosed.

Also of interest is the fact that the Stage 1 unpaired tone and water presentations for Group $U$ produced some pseudoconditioning of the JMR. However, the depressed JM CR performance of Group U in Stage 3 indicates that the occurrence of pseudo-CRs in Stage 1 did not make any substantial positive transfer contribution.

Since Group P approximated Group N's performance during Stage 3, no reacquisition savings effect was noted for the JM CR. This result may involve the intervention of opponent-motivational processes. As stated before, prior aversive conditioning has been shown (Scavio, 1974) to interfere with subsequent appetitive conditioning to the same CS. Therefore, the Stage 2 aversive NM conditioning accorded to Group $\mathrm{P}$ may have hindered the expression of appetitive motivational properties once established to the CS in Stage 1. Consequently, rapid JM CR reacquisition was prohibited.

Upon the completion of Stage 3, five CS-alone trials were administered to all groups to determine the strength of any residual NMR activity. Group NN, which had no stimulus presentations prior to Stage 3, yielded a 5\% NMR base rate. Therefore, the acquisition of JM CRs in Stage 3 did not also produce concomitant NM conditioning. The implication of this finding is that the comparatively rapid NM conditioning found for Group P in Stage 2 was not surreptitiously induced by Stage $1 \mathrm{JM}$ conditioning. For Groups P, U, and N, which all had received NM conditioning in Stage 2 , the CS-alone trials represented a measure of the persistence of the NM CR through Stage $3 \mathrm{JM}$ training. Group $\mathrm{P}(\overline{\mathrm{X}}=$ $52 \%$ ) maintained the highest performance level, followed by Groups $N(\bar{X}=36 \%)$ and $U(\bar{X}=18 \%)$. Therefore, the survival of the NM CR following JM conditioning was directly predicted by the overall NM CR performances recorded in Stage 2. An analysis of variance on percentage of NM CRs on the CSalone trials for Groups $\mathrm{P}, \mathrm{U}$, and $\mathrm{N}$ yielded a significant Groups effect $[F(2,33)=4.60, p<.05]$. Comparison tests following the analysis confirmed that the individual group performances were all reliably different from one another ( $\mathrm{ps}<.05$ ).

\section{Stage 4}

Figure 4 presents the percentage of NM CRs for all groups in blocks of 10 trials over the single Stage 4 session. For Groups P, U, and N, Stage 4 tone-andshock pairings represented reacquisition training for the NM CR originally established in Stage 2. As the figure shows, the asymptotic performance levels of Groups P, U, and N, observed at the conclusion of Stage 2, were restored within the first 10-trial block. Group NN, which had had no previous NM conditioning, gave far fewer NM CRs than any other group in Stage 4. An analysis of variance, performed upon the percentage of NM CRs in blocks of 10 trials, revealed significant effects for Groups $[\mathrm{F}(3,44)$ $=66.20, \mathrm{p}<.01]$, Blocks $[\mathrm{F}(2,88)=27.40, \mathrm{p}<$ $.01]$, and the Day by Blocks interaction $[F(6,88)=$ $2.31, \mathrm{p}<.051$. Comparison tests on the overall means of Groups $P(\bar{X}=88 \%), U(\bar{X}=82 \%)$, and $\mathrm{N}(\overline{\mathrm{X}}=83 \%)$ failed to detect significant differences. However, all three of these means were significantly different $(\mathrm{ps}<.01)$ from the mean of Group NN $(\bar{X}=14 \%)$. Thus, reacquisition was essentially identical, even though Groups $\mathrm{P}, \mathrm{U}$, and $\mathrm{N}$ displayed statistically different NM CR levels on the five CSalone trials given at the conclusion of Stage 3.

The rapidity of the reacquisition would appear to indicate tht Stage $3 \mathrm{JM}$ conditioning produced no long-term detrimental effects on NM conditioning. 


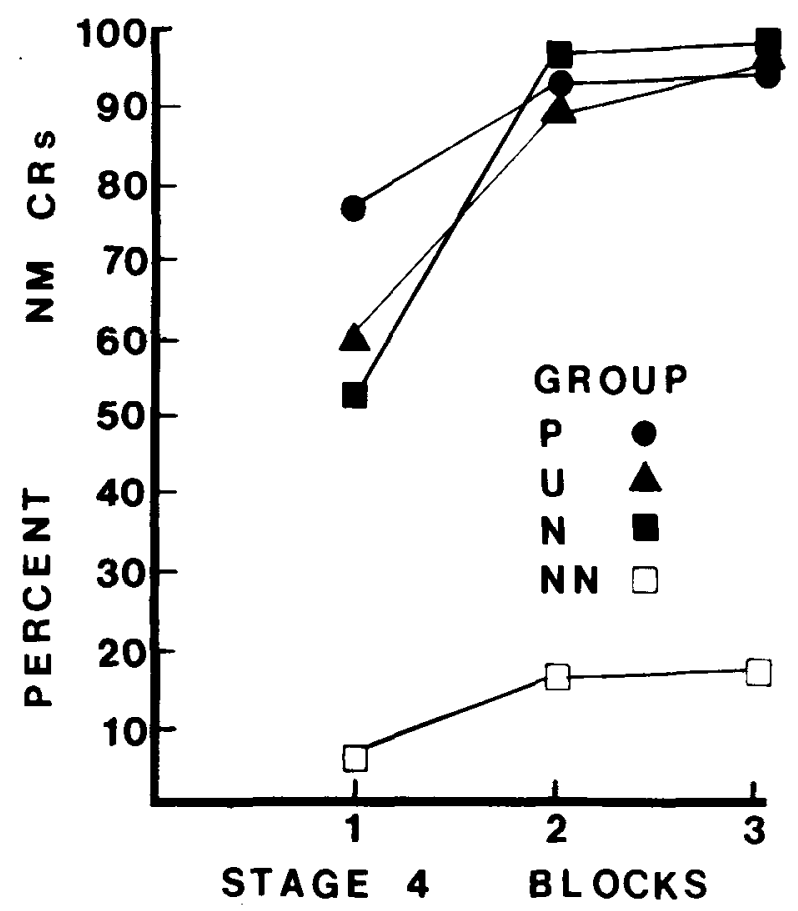

Figure 4. Mean percentage of nictitating membrane (NM) CRs plotted for all groups over blocks of trials in the Stage 4 training session.

This strong NM CR reacquisition following JM conditioning contrasts with the failure of the JM CR to show savings following NM conditioning. Therefore, another indication is provided of the asymmetry in appetitive-aversive interactions.

Finally, the finding that Group $U$ reacquired the NM CR at the same rate as Groups $\mathrm{P}$ and $\mathrm{N}$ implies that the inhibitory effects, generated by the Stage 1 unpaired tone and water deliveries and expressed in Stage $2 \mathrm{NM}$ and Stage $3 \mathrm{JM}$ conditioning, did not persist into Stage 4.

\section{DISCUSSION}

The major findings of the present experiment were that prior paired and unpaired tone and water presentations, delivered in appetitive JM conditioning, respectively facilitated and hindered subsequent aversive NM conditioning to the tone. When these effects are compared to results of previous work investigating how prior aversive conditioning influences appetitive conditioning to the same CS, a reversal in transfer outcomes is noted. Thus, prior paired (Scavio, 1974) and unpaired (Bromage \& Scavio, 1978) tone and shock presentations, given in aversive NM conditioning, respectively, interfered with and augmented appetitive JM conditioning to the tone. The asymmetry in appetitive-aversive interactions was indicated further by the present findings of reacquisition savings for the NM CR following appetitive conditioning, whereas no savings appeared for JM CR reacquisition following aversive conditioning.
The above evidence forces a reconsideration of the opponent-process position regarding appetitiveaversive interactions. According to opponent-process theorists (e.g., Konorski, 1967; Miller, 1963; Rescorla $\&$ Solomon, 1967), the affective dimension of the CS must first cause excitation in the corresponding motivational system so that reciprocal inhibition of the opposite system can occur. The substantial research on fear conditioning (e.g., Miller, 1948, 1951; Mowrer, 1947) is consistent with the proposal that CSs, paired with aversive reinforcers, become motivational elicitors. Given that increments in the aversive motivational system are followed by decrements in the appetitive motivational system, the negative transfer effect of aversive CS presentations upon the occurrence of appetitively reinforced behaviors (e.g., Estes \& Skinner, 1941; Konorski \& Szwejkowska, 1956; Scavio, 1974) is explained by the opponent-process model. Although the opponentprocess model claims that CSs paired with appetitive reinforcers should be motivational elicitors as well, other accounts produce another conclusion. Specifically, Hull (1943, p. 100) proposed that presentations of appetitive CSs elicit conditioned consummatory reactions whose effects are to reduce appetitive motivational strength. If this is so, the opponentprocess position must conclude that appetitive CS presentations, by reducing appetitive motivation, would produce disinhibition of the aversive motivataional system thorugh reciprocal interconnections. Thus, the observed acceleration of aversive NM conditioning following appetitive training to the CS, as well as the findings of other experiments showing the potentiating effects of appetitive CSs upon aversively reinforced behaviors (Bacon \& Bindra, 1967; O'Neill \& Biederman, 1974; Overmier \& Payne, 1971), would be consistent with the revised opponentprocess model. It is important to note that Konorski (1967, pp. 275-286) also considered the possibility that aversive CSs induce, whereas appetitive CSs reduce, motivation. Therefore, Konorski anticipated the above version of the opponent-process model which allows for asymmetrical transfer effects of aversive and appetitive CSs in interaction experiments.

A complete account of appetitive-aversive interactions may require consideration of still other mechanisms. The present findings that prior unpaired tone and water presentations exert negative transfer effects upon aversive NM and appetitive JM conditioning can be related to the salience properties of the CS as proposed by Mackintosh $(1973,1975)$. Briefly, Mackintosh has considered that the salience value of a CS is a multiplier of associative formation. A CS, paired with a reinforcer, should receive increments in salience, whereas a CS given in an unpaired manner with a reinforcer should receive decrements in salience. Finally, Mackintosh (1975, p. 290) hypothesized that changes of CS salience or associability are reinforcer specific. Therefore, the negative 
transfer effect of unpaired tone and water presentations upon subsequent JM conditioning when these stimuli were paired together is easily predicted by Mackintosh's salience theory. However, the interfering effects of the unpaired tone and water presentations upon aversive NM conditioning to the tone suggests that CS salience effects can operate across the hedonic boundaries of reinforcers. Therefore, the present experiment not only implicates a salience factor in appetitive-aversive interactions, but also extends the properties of CS salience beyond Mackintosh's original proposals.

The use of transfer designs to infer the properties of CSs has the potential risk of confounding by the presence of peripheral response interactions (cf Dickinson \& Pearce, 1977; Trapold \& Overmier, 1972). Thus, a positive or negative transfer effect may occur simply because mutually facilitatory or antagonistic behaviors are elicited by the CS and/or reinforcer. In the previous work (Bromage \& Scavio, 1978; Scavio, 1974), the joint occurrences of NM and JM CRs in the test stage of the transfer experiments were found to be statistically independent events. This ruled out the possibility that response system confoundings were responsible for the transfer effects. In the present experiment, test trials given to Group NN following Stage 3 JM conditioning revealed no concomitant NM CR formation. Hence, the positive transfer effect of prior tone-and-water pairings upon aversive NM conditioning was not due to response system carry-over across different reinforcers.

\section{REFERENCES}

Bacon, W. E., \& Bindra, D. The generality of the incentivemotivational effects of classical conditioned stimuli in instrumental learning. Acta Biologiae Experimentalis, 1967, 27, 185-197.

Bromage, B. K., \& Scavio, M. J., Jr. Effects of an aversive $\mathrm{CS}+$ and $\mathrm{CS}-$ under deprivation upon successive classical appetitive and aversive conditioning. Animal Learning \& Behavior, 1978, 6, 57-65.

Coleman, S. R., \& Gormezano, I. Classical conditioning of the rabbit's (Oryctolagus cuniculus) nictitating membrane response under symmetrical CS-US interval shifts. Journal of Comparative and Physiological Psychology, 1971, 77, 447-455.

Dickinson, A., \& Pearce, J. M. Inhibitory interactions between appetitive and aversive stimuli. Psychological Bulletin, 1977, 84, 690-711.

Estes, W. K., \& Skinner, B. F. Some quantitative properties of anxiety. Journal of Experimental Psychology, 1941, 29, $390-400$.

Goodkin, F. Rats learn the relationship between responding and environmental events: An expansion of the learned helplessness hypothesis. Learning and Motivation, 1976, 7, 382-393.

Gormezano, I. Classical conditioning. In J. B. Sidowski (Ed.), Experimental methods and instrumentation in psychology. New York: McGraw-Hill, 1966.

Gormezano, I., Schne iderman, N., Deaux, E., \& Fuentes, I. Nictitating membrane: Classical conditioning and extinction in the albino rabbit. Science, 1962, 138, 33-34.

GraY, J. A. The psychology of fear and stress. New York: McGraw-Hill, 1971.
Hull, C. L. Principles of behavior: An introduction to behavior theory. New York: Appleton-Century-Crofts, 1943.

KonORSKI, J. Integrative activity of the brain: An interdisciplinary approach. Chicago: University of Chicago Press, 1967.

Konorski, J., \& Szwejkowska, G. Reciprocal transformations of heterogeneous conditioned reflexes. Acta Biologiae Experimentalis, 1956, 16, 95-113.

Mackintosh, N. J. Stimulus selection: Learning to ignore stimuli that predict no change in reinforcement. In R. A. Hinde \& J. Stevenson-Hinde (Eds.), Constraints on learning. London: Academic Press, 1973.

Mackintosh, N. J. A theory of attention: Variations in the associability of stimuli with reinforcement. Psychological Review, 1975, 82, 279-298.

Miller, N. E. Studies of fear as an acquirable drive: I. Fear as motivation and fear-reduction as reinforcement in the learning of new responses. Journal of Experimental Psychology, 1948, 38, 89-101.

Mille R, N. E. Learnable drives and rewards. In S. S. Stevens (Ed.), Handbook of experimental psychology. New York: Wiley, 1951

Mille R, N. E. Some reflections on the law of effect produce a new alternative to drive reduction. In M. R. Jones (Ed.), Nebraska Symposium on Motivation (Vol. 11). Lincoln: University of Nebraska Press, 1963.

Mitchell, D. S., \& GoRmezano, I. Effects of water deprivation on classical appetitive conditioning of the rabbit's jaw-movement response. Learning and Motivation, 1970, 1, 199-206.

Mowren, O. H. On the dual nature of learning-A re-interpretation of "conditioning" and "problem solving." Harvard Educational Review, 1947, 17, 102-148.

MOWRER, O. H. Learning theory and behavior. New York: Wiley, 1960 .

O'Nelll, W., \& Biederman, G. B. Avoidance conditioning as a function of appetitive stimulus pretraining: Response and stimulus transfer effects. Learning and Motivation, 1974, 5, 195-208.

Overmier, J. B.. \& PAYne, R. J. Facilitation of instrumental avoidance learning by prior appetitive Pavlovian conditioning to the cue. Acta Neurobiologiae Experimentalis, 1971, 31, 341-349.

Rescorla, R. A., \& Solomon, R. L. Two-process learning theory: Relationships between Pavlovian conditioning and instrumental learning. Psychological Review, 1967, 74, 151-182.

Scavio, M. J., JR. Classical-classical transfer: Effects of prior aversive conditioning upon appetitive conditioning in rabbits (Oryctolagus cuniculus). Journal of Comparative and Physiological Psychology, 1974, 86, 107-115.

Smith, M. C., DiLollo, V., \& Gormezano, I. Conditioned jaw movement in the rabbit. Journal of Comparative and Physiological Psychology, 1966, 62, 479-483.

Solomon, R. L., \& Corbit, J. D. An opponent-process theory of motivation: I. Temporal dynamics of affect. Psychological Review, 1974, 81, 119-145.

Trapold, M. A., \& Overmier, J. B. The second learning process in instrumental learning. In A. H. Black \& W. F. Prokasy (Eds.), Classical conditioning. II: Current research and theory. New York: Appleton-Century-Crofts, 1972.

\section{NOTE}

1. The opponent-process theory of appetitive and aversive interactions dealt with in this paper should not be confused with the opponent-process theory of emotion and motivation recently advanced by Solomon and Corbit (1974). Although a comparison of the two models would be interesting, it would take us too far afield.

Received for publication September 15, 1978; revision accepted October $11,1979$. 